\title{
What Defines a Conceptual Resource?
}

\author{
PAUL-MIKHAIL CATAPANG PODOSKY \\ University of Melbourne
}

\begin{abstract}
In recent social philosophical investigation, many theorists have relied on the idea that our social and epistemic dispositions depend on collective access to a shared set of concepts, or what I call a conceptual resource. What is not said in this literature is how such conceptual resources are individuated. To address this, I propose and provide an answer to The Resource Question: What is the relationship that must hold in order for a set of concepts to be the conceptual resource of a group of people? This question implies that a conceptual resource is not defined simply by the concepts that constitute it, nor solely by the group that it is attributed to. Instead, it is defined by a relationship between groups of people and sets of concepts. After surveying some possible answers, I settle on Communication: social agents must be able to use concepts in patterned interactions of communication. This answer controverts the intuitive position that social groups are bearers of conceptual resources. I argue that conceptual resources are only indirectly related to social groups.
\end{abstract}

\section{Introduction}

Call an explanation that concerns how concepts are involved in our social lives a macro-level theory of concepts. Such theories aim to explain the relationship between the social and epistemic behavior of individuals, and the stock of concepts that they have available to them. In recent times, there has been a trend in social philosophical investigation toward this kind of theorization. What is suggested is that individuals rely on a pool of culturally shared concepts that serve particular social functions. This pool of concepts is what I will refer to as a conceptual resource.

A surprising feature of this macro-level trend is that there is very little reference to existing literature on micro-level theories of concepts. Theories of this kind attempt to explain conceptual phenomena per se, that is, independent of any social or epistemic functions that concepts might serve. Theorists interested

Contact: Paul-Mikhail Catapang Podosky <pmpodosky@gmail.com> 
in micro-level conceptual phenomena aim to bring to light how it is that concepts are individuated, and, inter alia, what it takes to possess, acquire, and share them. ${ }^{1}$

What makes it surprising that these levels of inquiry rarely engage with one another is that commitments at one level have implications on commitments at the other: one's acceptance of a macro-level theory has substantial bearing on what one can say at the micro-level, and vice versa. For this reason, it is important for both macro- and micro-level theorists to get clear on their commitments at each level of conceptual inquiry. Not only should there be interest in the macrolevel functions of concepts, theorists should make explicit what micro-level entailments this commits them to.

In this paper, I identify an under-theorized aspect of the literature concerning the social epistemology of concepts that bridges a gap between these two levels. I ask a micro-level question about macro-level conceptual phenomena: What does it take for a set of concepts to be the conceptual resource of a group of people? I call this The Resource Question. As it stands, there is no explicit attempt to address this. Instead, it seems that there is an answer that is implicit in existing literature: take social groups for granted and explain how conceptual resources are related to them.

By bringing to light various theorists' macro-level commitment to social groups as the bearers of conceptual resources, I show that it fails to account for acceptable micro-level commitments about how conceptual resources are individuated. I argue that social groups are not the bearers of conceptual resources; they are not the relevant group to which conceptual resources are correctly attributed.

Alternatively, I suggest that we should abstract away from any particular group of people, or set of concepts, and individuate conceptual resources simply by the relationship that must hold between the two. That is, a conceptual resource is defined by a particular relationship between a set of concepts and a group of people, independent of any of the features of concepts or groups considered on their own. ${ }^{2}$

Ultimately, I suggest that the relationship that answers The Resource Question is Communication: social agents must be able to use concepts in patterned interactions of communication. At the end of the paper, I suggest how the use of concepts in communicative interaction indirectly relates social groups to conceptual resources.

1. There are too many micro-level theories of concepts to list. However, for a good summary of the different areas of the philosophy of concepts, see Margolis and Laurence (1999a; 1999b; and 2015).

2. That is, it is not to do with anything about the particular concepts in a set, or criteria that determines membership in a group, that individuates conceptual resources. 


\section{Current Literature on the Social Functions of Concepts}

Miranda Fricker (2007) introduced the notion of a hermeneutical resource to uncover epistemic wrongdoings that occur at the level of social structure. Broadly speaking, a hermeneutical resource is a pool of concepts that social agents draw from for two important reasons. ${ }^{3}$ First, they aid cognitive agents in knowledge acquisition. An agent experiences the world, and their experience is rendered intelligible through the use of concepts; that is, interpretive assets that mediate between experience and reality. Second, they make possible knowledge transmission. When an agent successfully interprets their experience, such experience may only be rendered intelligible to themselves. However, since hermeneutical resources are shared between members of a given group, communicating conceptualized experience becomes possible within this group.

Given these roles, a hermeneutical resource can be a site for injustice. There are cases where a hermeneutical resource lacks particular concepts that would enable socially marginalized agents to make sense of their experience of oppression. Because of this, some agents are short of knowledge that is in their best interest to have. And further, this lack of concepts means marginalized agents cannot communicate experiences of oppression across social space. Knowledge of certain forms of oppression is not available to anyone. When either of these wrongdoings occur, Fricker calls this hermeneutical injustice. It is the injustice of having one's experience obscured from collective understanding due to structural identity prejudice (Fricker 2007: 155).

Sally Haslanger is another theorist who is interested in the role that concepts play in social life. Haslanger makes use of a theoretical posit employed in the social sciences called a schema 4 to explain social behavior (Haslanger 2012; 2013; 2015; 2016). Broadly, "schemas are clusters of culturally shared (public) concepts ... that enable us, collectively, to interpret and organize information and coordinate action, thought, and affect" (Haslanger 2015: 4). What is important about the way that Haslanger thinks about pools of concepts is their role in coordination. In line with Fricker, Haslanger believes that concepts aid agents in knowledge acquisition. They enable agents to interpret experience in order to

3. Strictly speaking, my formulation here isn't correct. Fricker suggests that the notion of a hermeneutical resource includes more than just concepts. In addition to concepts, it consists of expressive tools (e.g., terms, phrases, and culturally inflected ways of speaking). Further, Crerar (2016) suggests that our understanding of hermeneutical resources should include an expressively free environment. This is an environment in which individuals "can put their conceptualinterpretative resource to good hermeneutical effect" (2016: 195). For my purposes, however, it will suffice to talk solely about concepts. After all, there is still a question about how it is that concepts are related to groups.

4. For more literature on schemas see Sewell (1992), Howard (1994), and Hollander and Howard (2000). 
have knowledge or understanding of the world. However, Haslanger further believes that concepts are indispensable in coordinating our social behavior, in mind and action. When schemas are internalized by agents, they become the basis of behavioral and emotional dispositions (2015:4). Hence, when schemas are collectively internalized, social agents can coordinate effectively and efficiently.

I will call the pool of concepts that Fricker and Haslanger ${ }^{5}$ suggest are important in understanding how we collectively interact conceptual resources. ${ }^{6}$ That is, a conceptual resource performs the social functions of (I) aiding agents in knowledge acquisition, (2) making possible knowledge transmission, and (3) coordinating action, thought, and affect. A theory of conceptual resources must be able to explain these functions.

\section{The Resource Question}

This paper offers an answer to the following question:

The Individuation Question (IQ): What defines a conceptual resource?

One might be tempted to offer as an answer to IQ that an individual concept, taken alone, is a conceptual resource in its own right. After all, it appears to be a tool with which an agent can render intelligible their experiences. However, in keeping with Fricker and Haslanger, my interest is in the notion of a conceptual resource that concerns a pool of concepts. Another temptation one might have is to suggest that however a conceptual resource is defined, it is a pool of concepts attributable to an individual. Again, in keeping with Fricker and Haslanger, a conceptual resource is a pool of concepts that is shared by a particular group of people. Given this, we can reframe IQ as the following question:

The Resource Question (RQ): What is the relationship $R$ between a group of people $F$ and a set of concepts $C$ such that if $R$ obtains, then $C$ is the conceptual resource of $F$ ?

5. There are other theorists who make use of shared concepts. Notable examples are Cristina Bicchieri (2017) in her discussion on schemata and their involvement in social norms, and Jason Stanley (2015) in his discussion of an epistemic characterization of flawed ideology.

6. Elisabeth Camp distinguishes between concepts in the philosophical sense, and concepts in the psychological sense. Philosophical concepts are word-like representational structures that function as "stable, arbitrary, re-combinable bits" (Camp 2015a: 593); and psychological concepts (characterizations) are representational structures that are "contextually malleable, intuitive, and holistic" (2015a: 591). Both of these models of concepts capture the interpretive tools in a conceptual resource. 
An answer to RQ requires that in order to know whether a set concepts is a conceptual resource, we need to know more than just that is it associated with a particular group. More precisely, we need to know what this association is. In other words, a conceptual resource is defined by a particular relationship that holds between a set of concepts and a group of people. An answer to RQ is an answer to IQ.

Two deflationary answers to RQ can be given. Both were suggested above. One might push back and offer the following: a conceptual resource is just any individual concept taken on its own. Call this Conceptual Atomism.

Conceptual Atomism: There is no relationship $R$ that holds between a set of concepts $C$ and a group of people $F$, since individual concepts, taken alone, are conceptual resources in their own right. 7

Alternatively, one might argue that a conceptual resource is simply the set of concepts that an individual possesses, not a set of concepts attributable to a group. Call this Conceptual Resource Solipsism.

Conceptual Resource Solipsism: There is no relationship $R$ that holds between a set of concepts $C$ and a group of people $F$, since conceptual resources are attributable to individuals, not to groups.

I bring up these deflationary answers to make explicit the theme of this paper. It is about social philosophy: social epistemology and social coordination. Specifically, it is about the patterned interaction of individuals with respect to a set of concepts. For this reason, Conceptual Atomism and Conceptual Resource Solipsism cannot be answers to RQ. They cannot account for the social functions of concepts described by Fricker and Haslanger. Why not?

Gaile Pohlhaus Jr. suggests that feminist epistemology has taught us that "knowers are interdependent insofar as the [concepts] and tools with which we know operate collectively, not individually" (Pohlhaus 2012: 718). This is to say that we come to have understanding of the world with the use of concepts that are shared, and that these concepts are sustained and maintained by their role in coordinating agents who recognize them (2012: 718). For this reason, according to Pohlhaus, "a concept that in principle can be followed by only one person is not really a concept" (2012: 718). Put more bluntly, concepts link social agents together.

On top of this, the concepts that constitute a conceptual resource form an in-

7. I want to thank William Tuckwell for bringing this answer to my attention, and pushing me to see its merits. 
terconnected web, a network of concepts with varying degrees of interrelations. In other words, conceptual resources are holistic. ${ }^{8}$ When one comes to acquire or deploy a concept, one will situate it within a network of concepts that allows for certain inferences to be made. ${ }^{9}$

These two claims are related: Social agents are linked together in virtue of their shared access to a set of interrelated concepts that they are able to draw certain inferences from. In the cognitive sciences, an interconnected web of concepts that performs this role is called a semantic network. ${ }^{10}$ And this network is shared by members of a thinking and speaking community. What is important about semantic networks is that conceptual understanding depends on this interconnected web, and the inferences that we are able to draw influence the ways in which we expect others to behave, and how we should respond to such behaviour (Bicchieri 2017: 134). Thus, when a concept in a semantic network is activated, it will prime highly related concepts for activation, and we interpret the world, and decide on our actions, on the basis of these concepts (2017: 133). To summarize, the interconnectivity of agents relies on their access to a shared, interconnected web of concepts that serves as the basis for epistemic, behavioral, and emotional dispositions.

With this in mind, I propose that a set of interconnected concepts, and hence interconnected people, provides the framework for which the social functions of knowledge acquisition, knowledge transmission, and social coordination is possible. That is, one can only: acquire knowledge insofar as one is able to situate a concept within an interconnected web; transfer knowledge insofar as knowers are able to draw the same inferences between concepts; and coordinate action, thought, and affect insofar as there is mutual understanding that when a concept is deployed that certain behavior is expected from those to whom the concept applies. Further, there is a community of thinkers and speakers that sustain and maintain the concepts that acquisition, transmission, and coordination are dependent on.

A satisfactory explanation of the social functions that we're interested in requires that we think of conceptual resources holistically and communally. Hence, the atomistic and solipsistic approaches cannot give us satisfactory explanations.

8. This thought is in the inferentialist spirit of Block (1987), Harman (1987), Field (1977) and Peacocke (1992), without committing to the idea that inferences determine the semantic content of concepts.

9. I don't want to be committed to anything more than I need to be here. The suggestion is that conceptual resources are, minimally, moderately holistic. This means that it is not necessary that conceptual resources are constituted such that every concept must be related to every other. It might allow that there are just clusters of related concepts.

10. In the cognitive science literature on semantic networks, concepts are referred to as schemata (Fiske \& Taylor 1991; McClelland, Rumelhart, \& PDP Research Group 1986; and Rumelhart 1998). 
On the holistic and communal model, however, concepts become resources, or more appropriately are a part of a resource, in virtue of their interrelations. Concepts can serve certain social functions because they form an interconnected web sustained and maintained by an interconnected community.

One might object to the formulations of Conceptual Atomism and Conceptual Resource Solipsism that I have offered on the grounds that it is, perhaps, too strong to suggest that such answers are committed to there being no relationship between a set of concepts and a group of people. This is because the Atomist and Solipsist can say that the relationship between a set of concepts and a group of people is derivative, where the metaphysically fundamental relationship is either between a concept and individual/group (Atomist), or between an individual and concept/set of concepts (Solipsist). ${ }^{11}$

There are two things that we can say in response. First, we can deny that the relationship between concept and individual/group or individual and concept/set of concepts is fundamental. This is because the notion of 'fundamental' should be understood in terms of what relationship explains the social functions of concepts (or conceptual resources) - and as we have just seen, neither Atomism nor Solipsism can do this. Second, we can accept that the relationship between concept and individual/group or individual and concept/set of concepts is fundamental, and that the relationship between a group of people and a set of concepts is derivative. However, this just shifts RQ to another metaphysical order: What is the derivative relationship $R$ between a group of people $F$ and a set of concepts $C$ such that if $R$ obtains, then $C$ is the conceptual resource of $F$ ? Rephrasing the question in this way still demands an answer as to how groups of people are related to sets of concepts. Neither Atomism nor Solipsism can provide this answer on their own. Hence, we must look elsewhere for answers.

\section{The Social Group Answer}

I will now offer an intuitive answer to RQ. It is an answer that ultimately fails, but nevertheless sheds important light on what a good answer must consist of.

$\mathrm{RQ}$ is not an explicit research question in any existing literature. There has been no attempt to discern the conditions under which a set of concepts is a conceptual resource. However, there is plenty of literature on the topic of how conceptual resources are involved in our social lives. What seems to be implicit in this kind of literature is that conceptual resources are attributed to social groups. That is, social groups are bearers of conceptual resources. And this is a convincing way to think. The suggestion is that however one thinks a social group is

11. Thank you to an anonymous reviewer for pointing out this objection. 
defined, a conceptual resource will be defined in some way that is relevant to this. I will now take time to consider some of this literature.

Miranda Fricker claims that there is a collective hermeneutical resource, a stock of concepts that can, by and large, be possessed by anyone and that enables conceptualized experience to be conveyed across social space. In other words, the collective hermeneutical resource consists of those concepts that are "held in common" (Fricker 2017: 4). Things go awry, according to Fricker, when one social group dominates the process by which concepts are introduced into the collective hermeneutical resource. What this means is that the concepts that are part of the collective hermeneutical resource are there in virtue of structural inequality insofar as there are social groups who exert their social power and they influence, to a significant degree, the discussion of what social experiences are to be captured by shared concepts. The effect, of course, is that the experiences of the more powerful groups are rendered intelligible and communicable across social space, whereas the experiences of members of less powerful groups are left misunderstood or are unjustly ignored. To reiterate, Fricker calls this 'hermeneutical injustice'.

There have been different responses to Fricker's formulation of hermeneutical injustice. Importantly, there have been concerns with respect to the characterization of hermeneutical injustice as being a matter of interpretive deficiencies in the collective hermeneutical resource. The common theme in each of the works that I will discuss is the accusation that Fricker ignores alternative resources that are unique to social groups. I will spend time on three authors: José Medina (2013), Rebecca Mason (2011), and Kristie Dotson (2012).

Medina wants to put pressure on Fricker's idea of 'collective understanding'. He takes exception to the notion of a collective hermeneutical resource since it suggests that we can pool together the hermeneutical resources of different social groups and create "some kind of exhaustive inventory" (Medina 2013: 103). However, Medina argues that a society that contains multiple social groups will have variegated ways of talking and making sense of experience, and

it is not at all clear that there is always some unified hermeneutical realm where the interpretative resources of all can be pooled; and even within distinctive publics with their peculiar resources, there will be differences, deviations, and idiosyncratic supplemental interpretative tools. (2013: 104)

For Medina, it is important that one understand that there is interpretative diversity across social groups, and that this means that we should not think that when a collective social body as a whole does not understand that therefore no one understands. 
In line with Medina's suggestion that conceptual resources are distinctive of social groups, Rebecca Mason also claims that Fricker does not accommodate interpretative diversity. Mason is careful not to ignore non-dominant discursive realms. She argues that "Fricker conflates collective hermeneutical resources with that which is articulated and taken up in those discourses from which subjects are systematically marginalized. This conflation means that 'collective' hermeneutical resources function as de facto dominant on her view" (Mason 2011: 299-300). What this mean is that Fricker does not distinguish between resources that are used in dominant discourse, and those that are used elsewhere: there is one and only one hermeneutical resource and it consists of the concepts that are (mostly) used to render intelligible the experiences of those members of society with social power. For Mason, this is a grave oversight. She accuses Fricker of ignoring non-dominant hermeneutical resources; namely, those concepts used in non-dominant discursive realms to make sense of, and make communicable, the experiences of marginalized groups. Mason believes that Fricker does not take into account the hermeneutical resources of particular social groups.

Lastly, Kristie Dotson, like Medina and Mason, argues that we are not all dependent on the same hermeneutical resource. Individuals, who belong to different and distinctive social groups, make use of non-dominant concepts. Like Mason, Dotson accuses Fricker of thinking that there is only one hermeneutical resource that individuals draw on in order to render intelligible their experiences. However, this disregards a particular way that members of privileged groups perpetrate a kind of epistemic injustice, what Dotson (2012) calls contributory injustice. This kind of injustice relies on there being multiple hermeneutical resources, and importantly resources that do a better job of making sense of certain experiences than others. The injustice occurs when a member from a privileged group in wilful ignorance uses ill-fitting concepts to make sense of a marginalized person's oppressive experience, and therefore lacks knowledge of important facts about the world.

What we can see from Medina, Mason, and Dotson is that marginalized groups can make use of concepts that are not part of the dominant hermeneutical realm. Given that marginalization is a function of the power dynamics between social groups, there is a tight connection between social groups and nondominant hermeneutical resources. And, despite the charges against her, Fricker also stresses this point by suggesting that,

One way of thinking about the epistemological suggestion that social power has an unfair impact on collective forms of social understanding is to think of our shared [hermeneutical resource] as reflecting the perspectives of different social groups, and to entertain the idea that relations of unequal power can skew shared hermeneutical resources so that the 
powerful tend to have appropriate understanding of their experiences, whereas the powerless are more likely to find themselves having some social experiences through a glass darkly, with at best ill-fitting meanings to draw on in the effort to render them intelligible. (Fricker 2007: 148, my emphasis).

I don't wish to offer a solution as to who wins between Miranda Fricker and her critics. What I want to make explicit, though, is that in the literature that speaks on the topic of hermeneutical resources, much of it relies on them being associated with social groups. Because of this, it is tempting to think that hermeneutical resources are defined in some way that relates to social groups; or in other words, that social groups are bearers of hermeneutical resources.

A theorist who makes this particular claim most explicit is Trystan S. Goetze (2018). Goetze suggests that in instances of hermeneutical marginalization at the collective level, members of oppressed groups can create their own interpretive tools in order to make sense of their unique experiences. This is called hermeneutical dissent (2018: 74). Hermeneutical dissent requires that there be local and global hermeneutical resources. Goetze doesn't offer definitions of either local or global hermeneutical resources. However, it is clear that he is interested in how marginalized social groups can suffer from hermeneutical injustice, even through dissent. In virtue of this, it is reasonable to think that Goetze is thinking of local hermeneutical resources as attributed to (marginalized) social groups.

Given this suggested link between social groups and hermeneutical resources, how might this pose an answer to RQ? The suggestion might be that the relationship that holds between a set of concepts and a group of people will be sensitive to what group of people one is interested in. Specifically, if our interest is in social groups, then RQ must tell us how conceptual resources are associated with groups qua social group. This produces two possible answers. One more plausible than the other. Call the less plausible one the Constitution Social Group answer:

Constitution Social Group: For a group of people $F$ and a set of concepts $C, C$ is the conceptual resource of $F$ if and only if $F$ is a social group, and $C$ plays a part in constituting $F$.

This answer suggests that a social group is the bearer of a conceptual resource in virtue of the fact that a set of concepts partly constitutes the social group. What does this mean? It's unclear. One way that we might make sense of this is by suggesting that for some social group $G$, it is partially constituted by the very concept of $G$-that is, for someone to be a member of $G$, they must possess the 
concept of $G .{ }^{12}$ For example, one can belong to a particular gender in virtue of identifying with (and hence possessing) the concept woman. However, Constitution Social Group faces a problem. We expect that for most groups (if not all), they possess concepts that go beyond $G$-a group can possess many concepts in addition to G. Constitution Social Group cannot explain how these additional concepts are part of the conceptual resource of $G$.

Perhaps we should instead be interested in whether a set of concepts is used by members of a social group in the patterned interactions that make a group of people a social group. This is much more plausible. Call this the Interaction Social Group answer:

Interaction Social Group: For a group of people $F$ and a set of concepts $C, C$ is the conceptual resource of $F$ if and only if $F$ is a social group and $C$ contains the concepts used by members of $F$ in the patterned interactions that make $F$ a social group.

This answer to RQ suggests that in order for a conceptual resource to be attributed to a group of people, the group of people must be a social group, and that the set of concepts that constitutes the conceptual resource must be attributed to the group of people in virtue of being a social group. Specifically, the patterned interactions that define a social group involve the use of a particular set of concepts. This is to say that conceptual resources and social groups are directly related: Social groups are bearers of conceptual resources.

In order to assess the plausibility of this answer, it's important that we have some idea of what a social group is, and whether the patterned interactions that determines whether a group of people is a social group have anything to do with concepts.

The kinds of social groups that I am interested in are the ones that were spoken about above: those that are involved in power dynamics, and hence those that can be hermeneutically marginalized or advantaged. This includes gender, race, class, ability, and the like. So, we can ask more specific questions: What is it that makes a woman belong to the social group woman? This is a tough question that has many contested answers. One broad answer to this question, that contemporary theorists by and large agree on, is that social groups are socially constructed. Particularly, they are constructed by things such as social roles. ${ }^{13} \mathrm{As}$ Popa-Wyatt and Wyatt (2017: 10) put it, roles carry information about expected and permissible behaviour, determine social status, and attribute rights and responsibilities. Further, "it is through roles that tasks in society are allocated and

12. Thank you to an anonymous reviewer for bringing this point to my attention.

13. For more on this, see Haslanger (1995) and Mallon (2007). 
arrangements are made to enforce their performance" (Goffman 1961: 77). Human interaction is governed by these roles. And roles define social groups.

Given the social functions of concepts that we have discussed-knowledge acquisition, knowledge transmission, and social coordination - we might think that concepts are what social roles rely on in order for individuals to enact the behavior that is expected and permitted of them. ${ }^{14}$ That is, concepts are necessary for enacting social roles. If this is right, then we might suspect that Interaction Social Group is the right answer to RQ. Why? There are concepts that members of a social group $F$ use in patterned interactions (social role) that make $F$ a social group. For example, the social group woman is (unjustly) partly defined by a social role that, say, women are caretakers. In order for this role to be successfully assigned, and enacted, individuals need to possess the concept CARETAKER and recognize, to some extent, that being a caretaker applies to them.

Nevertheless, there are good reasons to doubt Interaction Social Group. First, Interaction Social Group does not give us a principled way to define conceptual resources. Though many will want the notion of a conceptual (hermeneutical) resource to be related to social groups in some way, many will also want there to be a collective conceptual resource in the way that Fricker has suggested: a conceptual resource that is held in common across social groups (e.g., Goetze's 'global' resource). However, there is no social group that corresponds to a collective conceptual resource. Hence, according to Interaction Social Group, it isn't ontologically appropriate to say that the collective conceptual resource is a conceptual resource. For someone who wants to salvage Interaction Social Group, they might suggest that the collective conceptual resource is the intersection of all conceptual resources of social groups. But this just appears to be ad hoc. A better answer to RQ will not bring about this concern. ${ }^{15}$

Second, Interaction Social Group can't explain how conceptual use brings together the relevant concepts that we intuitively take to be attributable to a social group. Take the social group woman. Interaction Social Group is supposed to tell us that in order for a set of concepts to be the conceptual resource of woman, the set of concepts must be used by members of woman in the patterned interactions that makes woman a social group. But it's unclear why we should accept such a strong criterion. For instance, it's reasonable to maintain that women, as a social group, have a conceptual resource, and it contains concepts that have nothing to do with their social role-it has nothing to do with whether or not they belong

14. This is kind of view is espoused by Haslanger $(2012 ; 2013 ; 2015 ; 2016)$ who says that in order to enact our social roles, we must possess schema-psychological structures that enable individuals to organize and respond to information.

15. One might suggest that 'society' is the social group that corresponds to the collective conceptual resource. This strikes me as controverting an intuitive idea of what counts as a social group. 
to woman. Take Fricker's most famous example. The concept SEXUAL HARASSMENT is something that we intuitively expect will be part of the conceptual resource of woman, but nevertheless it appears to play no role in the patterned interactions that makes woman a social group. If we expect that concepts must play a role in defining a social group, then we can't explain how women qua woman were able overcome hermeneutical marginalization when SEXUAL HARASSMENT was introduced as an interpretive tool.

Third, Interaction Social Group can't explain how conceptual use brings together the relevant individuals as belonging to the same social group. Take woman once more. Interaction Social Group implies that there is a set of concepts specifically used by women that makes woman a social group. However, all the concepts that we might think contribute to the social role that defines woman, we might also think are (or can be) possessed and deployed by those who are not women. Men can use these concepts too; they might take CARETAKER to apply to themselves, which in effect governs their behavioral and emotional dispositions. One would be hard-pressed to find precise reasons why the use of a concept contributes to membership to a social group for one person, but not for another.

Given these problems, there is no relationship that can be offered as an answer to RQ such that a set of concepts is the conceptual resource of a social group. Hence, social groups are not bearers of conceptual resources. This might prompt one to cast doubt on the existence of conceptual resources, or push one into something like Atomism or Solipsism. However, this concern should be tempered with optimism. There is an intuitive pull to the suggestion that conceptual resources are defined by conceptual use, independent of whether such use is related to social groups. Hence, we should look more closely at the nature of conceptual use, instead of the groups that use them. This is what I will do in the next section. Nevertheless, we should not ignore the intuition that conceptual resources and social groups are closely related. It would be a strange result if the relationship that I offered as an answer to RQ turned out not to make sense of how in-group members of social groups communicatively interact with one another given their own unique interpretive assets that often exclude the possibility of communication with out-group members. Hence, we should expect that any answer to RQ will be able to explain how the use of certain concepts is often bound to a particular social group, even if indirectly. I will discuss this in Section 7 .

\section{The Communication Answer}

In the previous section I argued that social groups are not bearers of conceptual resources. In other words, conceptual resources are not directly related to social 
groups. With this in mind, I will now offer another answer to RQ: Communication. This suggestion is more plausible as it accords with what I suggested above about conceptual use. It is the idea that a conceptual resource is constituted by concepts that are used by agents in patterned interactions of communication. Hence, it provides the following answer to RQ:

Communication: $C$ is the conceptual resource of $F$ if and only if the concepts in $C$ are used by the members of $F$ to communicate.

This answer is distinct from Interaction Social Group insofar as it leaves unspecified what existing groups can be substituted for $F$. It does not take for granted that there are ready-made social groups that conceptual resources must be associated with in order to answer RQ. On this account, social groups aren't the bearers of conceptual resources. ${ }^{16}$

What makes Communication appealing is that any alternative answer to RQ that entails that a group of agents cannot communicate given the set of concepts that is supposed to be their conceptual resource will not be able to explain one of the social functions that a conceptual resource is intended to serve, namely, knowledge transmission. If a suggested answer to RQ proposed a relation $R$, where $R$ is intended to explain how $C$ is the conceptual resource of $F$, but the members of $F$ cannot use the concepts in $C$ to communicate with one another given $R$, then $R$ cannot explain how knowledge is transmitted through a community of speakers given $C$. In other words, if agents cannot communicate with one another, then $R$ is not the relation that must obtain such that $C$ is the conceptual resource of $F$.

It is clear that an answer to RQ would not permit such an extreme lack of communicative interaction. However, it might be possible that a group can have a conceptual resource, yet not every agent of the group can communicate with respect to every concept in the conceptual resource. This is a situation where for some group $F$ that has a conceptual resource $C, a$ and $b$ are members of $F$, yet $a$ possesses a concept $x$ of $C$, and $b$ does not, such that $a$ and $b$ cannot communicate with respect to $x$, yet nevertheless share $C$. In other words, $a$ and $b$ share the same conceptual resource, yet cannot communicate with respect to at least one of its concepts. That said, we might question why we should believe that $a$ and $b$ share the same conceptual resource if they cannot use $x$ to communicate with one another.

A negative response to this is to say that since $b$ cannot communicate to $a$

16. That is, the conditions under which a group of people is a social group does not play a role in determining whether a set of concepts is the conceptual resource of a group of people. This leaves open the possibility that social groups have access to a conceptual resource provided that the members meet the conditions of Communication. 
with respect to $x$, then $a$ and $b$ do not belong to the same group $F$ associated with a conceptual resource C. Call this Strong Communication.

Strong Communication: For a group of people $F$ and a set of concepts $C$, $C$ is the conceptual resource of $F$ if and only if all members of $F$ can communicate with one another using any of the concepts of $C$.

For someone inclined to think in this way, $b$ will not share a conceptual resource with $a$ even if $b$ possesses all of the other concepts in $C$ that each member of $F$, including $a$, possesses.

This answer defines $F$ by the ability of each member to communicate using a particular set of concepts, and because of this it gives us a radically different answer from Interaction Social Group. Strong Communication does not take existing social groups for granted, and even entails the counterintuitive conclusion that conceptual resources are really not that closely related to them. This is because the conditions for being a member of $F$ are stringent; it requires that each member possess all of the concepts in $C$ and is able to use any of those concepts to communicate. This will clearly not map neatly onto social groups, since it is likely that not all members of social groups possess the same concepts, and because of this, it won't be the case that each member can use such concepts in communication.

It might be tempting to adopt this answer since it provides a clear and clean solution to RQ. However, Strong Communication is, perhaps, too strong. This is for at least three reasons. First, given our commitment to explain how conceptual resources are related to social groups, it is highly unlikely that Strong Communication will allow us to do this. Second, it will entail that conceptual resources are quite sparse. This is because over a certain number of concepts it will be rare that any two people possess exactly the same concepts. Third, it will preclude people we intuitively find should be part of the group associated with a conceptual resource, namely the people who, under plausible conditions, would come to possess the concepts of $C$. Further, those who could plausibly come to possess the concepts of $C$ will be in a position where they could plausibly communicate with others using such concepts. Call an account that accommodates this last concern Weak Communication.

Weak Communication: For a group of people $F$ and set of concepts $C, C$ is the conceptual resource of $F$ if and only if all members of $F$ either can, or could plausibly, communicate with one another using any concept of $C$.

The merit of this view is that though members of $F$ may not actually possess all of the concepts of $C$, they are nevertheless in a position where they could plausibly 
acquire such concepts, and would eventually come to deploy them in communication. This answer can accommodate those who are still learning the concepts of their group (e.g., children). Importantly, this includes those who are socially situated such that, given proper reflection or more experience, they will come to acquire and use the concepts of their group. A possible advantage of this claim is that it can accommodate a sub-set of concepts in $C$ that are esoterically possessed, that is, those concepts that are only possessed by a minority of the members of $F$, yet nevertheless are still part of the conceptual resource of $F .{ }^{17}$ This is because if all members of $F$ are situated such that they could plausibly come to possess the concepts of $C$, even if a sub-set of concepts $A$ in $C$ are esoterically possessed, all members could plausibly possess the concepts of $A$, and in virtue of this they could plausibly use such concepts in communication. Hence, they satisfy the conditions of Weak Communication.

The importance of this point relates to standpoint theory. Standpoint epistemologists, following from Marx, argue that in virtue of occupying a certain position in a social structure, some agents, under strict conditions, have epistemically privileged access to certain facts about the world. For example, some Marxist feminist standpoint theorists argue that women bear a unique relation to the means of reproduction, and that this makes them particularly well positioned to understand flawed patriarchal ideology (Hartstock 1983; Rose 1983) And this privileged epistemic access to flawed ideology can be the grounds for activism with the ultimate aim of social justice. However, such privileged understanding requires the possession of particular concepts that may not be widely shared within a given group. But we may want to resist the idea that, in virtue of this, such concepts are not part of the conceptual resource of the group. Weak Communication can accommodate this.

Even with this in mind, there is an obvious downside to this view. It is not at all clear what is meant by 'plausibility'. What are the conditions under which a concept might be plausibly possessed or plausibly used in communication? It is hard to think of a satisfying answer to this concern. Too broad of a definition will entail that there are no distinctive conceptual resources, too narrow will entail that there are too many.

Intuition may be able to do some work for us. Relating to the point about standpoint theory above, we can think of cases where it is much more likely that someone will come to possess a concept simply in virtue of their social situatedness. For example, take a member from a Black community in the United States.

17. In the current political climate, it seems that there is a rapid and constant updating in what concepts are used to carve the world up. I have in mind concepts such as LGBTQIA+, CIS, POC, INTERSECTIONAL, etc. What is particularly interesting is that concepts of this kind have not yet fully reached common possession but nevertheless we might think that they are still part of our shared conceptual inventory. 
This member who is unfamiliar with, say, the concept wOKE is in a better position to acquire the concept than, say, a White member of the far-right. ${ }^{18}$ That is, it is plausible that the Black person will come to possess wокE, and in virtue of this it is plausible that they will be able to deploy the concept in communication. However, we might think that it is within the realm of plausibility for the White person to acquire wOKE too, even if it less plausible. Because of this, the White person satisfies the conditions of Weak Communication. This does not seem right to me. It might be possible for the White person to understand the concept as something that involves being socially conscious or aware, but for the Black person, given their social situatedness, it is likely that the concept wOKE is much richer than this, something inextricably tied to their social position. Insofar as this is right, and given that the White person cannot understand being woke in the way that the Black person can owing to differences in social situatedness, then it appears that there is something to be said about plausibility: it is much more plausible for the Black person to acquire the concept woKE as understood in their community than it is for the White person to acquire the same concept, since it may be impossible for the White person to acquire the concept at all, only a thinner, related one. ${ }^{19}$

This case may not be representative of many concepts. Because of this, it may be that the conditions of Weak Communication are easily satisfied, and hence there are few distinctive conceptual resources. It isn't clear to me that this is a bad outcome. What is important about accepting this kind of case is that it can accommodate non-dominant conceptual resources (see Mason 2011; Dotson 2012; Medina 2013; Goetze 2018). That is, alternative conceptual resources that are shared by a particular group of marginalized folk that deviate from, and challenge, dominant ways of thinking and speaking. This is important because, following from Medina, Mason, Dotson, and Goetze, a good theory of conceptual resources should be able to explain how agents can communicatively interact without buying into, at least not completely, the concepts of a dominant conceptual resource. Hence, so long as we can explain non-dominant interpretive practices, whether there are only few conceptual resources does not seem to be a problem.

I want to end this section by stating the same worry as above, but, again, tempered with some optimism. Given that we are unable to provide precise in-

18. An approximation of what the concept of wOKE as used in black communities is supposed to capture is being aware of the grip of implicit White ideological structures and how it can manifest, in particular with respect to law enforcement.

19. It may be possible for the White person to acquire the same concept but impossible to acquire the same, what Elisabeth Camp (2006; 2015a; 2015b) calls, characterization: clusters of features attributed to an individual that is structured by prominence and centrality. This is the much richer sense of 'concept' that is needed to perform the relevant social roles. 
dividuation criteria for conceptual resources, we might think that we should embrace something like Atomism or Solipsism, or be skeptical of conceptual resources altogether. However, Weak Communication appears to be a promising variation of Communication, and by no means do I think that I have given an exhaustive account of it here. It seems that a proper understanding of the conditions of Weak Communication needs a great deal of further explication, which is not possible in this paper.

\section{Pressure on Communication}

Why believe that Communication even answers RQ? It might appear that Communication as an answer to $R Q$, whether weak or strong, begs the question, or at the very least seems trivial. After all, we've already accepted that at least one of the functions of a conceptual resource is knowledge transmission, and communication just seems to be accounted for by this. To transmit knowledge is just to communicate it. Hence, it seems a bad suggestion to say that $C$ is the conceptual resource of $F$ because the members of $F$ use the concepts of $C$ to communicateof course they do. In this section I will outline two independent suggestions why Communication is a still a plausible answer to RQ despite this.

I take it that there is a meaningful difference between the role that something plays and the metaphysical reasons that contribute to the existence of that something. The latter is Brian Epstein's characterization of grounding; it is the metaphysical reasons in virtue of which some further fact obtains (Epstein 2015: $70-71$ ). For example, if we're interested in the role of a great leader (of a country, say) we expect that they will, minimally, act in the best interest of the people that they are leading. But we can also ask for the metaphysical reasons in virtue of which someone is a great leader. Or, in other words, what is the relationship between a leader and her people such that if the relationship obtains, then she is a great leader? Again, we might expect an answer that they, minimally, act in the best interest of the people that they are leading. Have we begged the question or answered trivially? It strikes me that no, our answer is perfectly sensible. It seems, instead, that the answer tells us that the role, in some sense, is grounded in the metaphysical reasons; it is grounded in what it takes to be a great leader. Why is the role of a great leader to, minimally, act in the best interest of the people that they are leading? Because that's what it takes to be a great leader.

We might wonder whether this same kind of reasoning applies to conceptual resources. The suggestion that we are concerned with is whether Communication is the metaphysical reason in virtue of which a conceptual resource obtains. But since one of the functions of a conceptual resource is for knowledge to be transmissible, then the conditions of Communication will be accounted for by this. Can 
the conditions of Communication be a role and also the metaphysical reason in virtue of which a conceptual resource obtains? It seems straightforward to say that they can. The reason is that the role is grounded in the metaphysical reason. We can ask: Why is one of the roles of a conceptual resource a condition stated in Communication? The answer: Because that's what it takes to be a conceptual resource.

If one is unsatisfied with this reasoning, another answer that might be more appealing is that Communication just follows directly from my interest in social philosophical concerns. The notion of a conceptual resource is group-based.

An individualistic explication of a conceptual resource would likely not entertain considerations about how such resources are shared. Instead, it would pay attention only to the way that an individual uses concepts when navigating the world. I have called this Conceptual Resource Solipsism. Such a view ignores how experience is embedded in a social system with multiple agents trying to communicate and coordinate their actions, thoughts, and emotions. If this is how one is disposed to think about conceptual resources then, of course, Communication won't be satisfying. After all, Communication entails that there is a group of people who share, and communicate with, the use of concepts, as well as coordinate their behaviour with respect to them. It is an answer to RQ.

I am not interested in the solipsistic way of thinking. My concern is social. It is for an explication of the dynamics of groups with respect to their relationship to a set of concepts. Because of this, a satisfactory answer to RQ must make sense of sociality, and Communication does just this. It is an answer that entails that there is a group of people for which communicating conceptualized experience is possible.

But with this in mind, we should ask why knowledge acquisition or social coordination can't be the basis of an answer to RQ, since they are also functions of conceptual resources. Concerning acquisition, the answer is that merely acquiring a concept, or set of interrelated concepts, that gives us knowledge of the world does not entail that such knowledge is transmissible, one of the roles of a conceptual resource. However, that a concept allows one to transmit knowledge does entail that knowledge has been acquired. Hence, acquisition cannot be the basis of an answer to RQ, where communication more plausibly is. It is possible for one to have acquired a concept that mediates between experience and reality, and yet not to be able to communicate conceptualized experience across social space.

Concerning the latter, it is not clear why social coordination cannot be the basis of an answer to RQ. This is because it makes sense of the social dynamics of groups. It is about concepts and the way that they are involved in socially coordinated activity. Because of this, I do think that it can be the basis of a candidate answer: 
Social Coordination: $C$ is the conceptual resource of $F$ if and only if the members of $F$ can use the concepts of $C$ to coordinate with one another.

Of course, this will come in weaker and stronger forms. For example, we might question whether all members of $F$ must be able to use all of the concepts of $C$. How one answers this question will determine the strength of the thesis.

A drawback of Social Coordination is that it does not account for knowledge transmission. It seems perfectly plausible that there can be fully coordinated groups without conceptual communicative interaction. This is to say that the actions of a group, coordinating in intelligent ways, may be a product of a shared set of concepts; however, this set of concepts fails to be a conceptual resource insofar as it does not entail that members of such a group use these concepts to communicate with one another. For example, a group of people might share the concept LINE, and they might coordinate their behaviour with respect to purchasing a good by forming a line, however at no time in this formation do the people ever communicate their conceptualized experience of lines to one another.

Conversely, Communication does accommodate social coordination. The fact people do communicate entails that they are socially coordinating with one another. Minimally, they are coordinating in conversation. And this minimal feat of coordination becomes the framework for more sophisticated forms of social coordination, whether in action, thought or affect. For example, the ability to communicate thoughts about a specific kind of fruit that is poisonous provides the basis for coordinated behaviour around the poisonous fruit, namely, we might make collective efforts to avoid it. This might develop into shared expectations where thought becomes coordinated; namely, everyone believes that everyone else will avoid that kind of fruit. And further still, this may coordinate emotion; namely, we may become collectively scared to go near the poisonous fruit. Hence, Communication accounts for all three of the social functions of conceptual resources.

\section{Communication and Social Groups}

Above I argued that a good answer to RQ should be able to tell us how it is that conceptual resources are related to social groups. I take this to be important for two reasons. First, it would be a theoretical deficiency if one could not explain how in-group members are able to communicatively interact in ways that are often to the exclusion of out-group members. And provided that social groups constitute well defined in-groups, then an answer to RQ should be able to explain how social groups acquire and transmit knowledge with the use of concepts, as well as to coordinate social behavior. Second, there has been immensely 
important work written on the nature of hermeneutical resources that explains how members of marginalized groups can dissent from dominant hermeneutical realms in order to render intelligible experiences that would have otherwise been ignored. ${ }^{20}$ This work is convincing, and an answer to RQ that cannot accommodate these findings is a significant drawback.

That said, there is no direct relationship between social groups and conceptual resources. In Section 4, I discussed three reasons why this is the case. However, I alluded to the possibility that conceptual resources can be indirectly related to social groups. Let me make clear what I mean by 'direct' and 'indirect'.

A direct relationship between a set of concepts $C$ and a group of people $F$ is one in which in virtue of $F$ and $C$ instantiating a particular relationship, $C$ is the conceptual resource of $F$. In other words, $F$ is the bearer of $C$. I have suggested that Communication is the relevant relationship that determines this fact.

An indirect relationship between a set of concepts $C$ and a group of people $G$ is one in which, $C$ is in fact the conceptual resource of $F$, but because $G$ and $F$ have (massively) overlapping members, $C$ becomes associated with $G$ even though $G$ is not the bearer of $C$ (since $G$ and $C$ do not sit in the relevant relationship that answers RQ). 'Association' can be understood as the tendency to attribute a conceptual resource to a particular group of people (i.e., a social group), even though the group of people to which the conceptual resource is often attributed is not the bearer of the concept resource.

Given that we want an answer to RQ to tell us how it is that social groups are related to conceptual resources, in this section I will explain how Communication provides an answer that suggests that this relationship is indirectCommunication explains the tendency to attribute conceptual resources to social groups, without suggesting that social groups are bearers of conceptual resources.

On face value it does not appear that Communication will be able to explain how conceptual resources are related to social groups. After all, it suggests only that for a set of concepts to be the conceptual resource of a given group of people, the members of the group must be able to use the set of concepts to communicate with one another. But given that the members that constitute the group directly related to a conceptual resource can communicate with one another without being a part of the same social group, it is not obvious how one might provide a satisfying explanation of the relationship between social groups and conceptual resources if we accept Communication. That said, there is an explanation available if we think about (1) how social groups are typically geographically located and (2) syndication in virtue of shared aims and goals.

With respect to (1), it is a typical feature of social groups that members are

20. See Mason (2011), Dotson (2012), Polhaus (2012), Medina (2013), Goetze (2018). 
in close spatial proximity to one another. Because of this, social coordination becomes a possibility, if not an urgency. Coordination becomes particularly important in response to finite resources. In a situation where individuals share a spatial area, they will need to organize their interactions in a way that allows them to make the most out of the resources that are available. An effective means to do this is through communicative interaction, the ability to convey information to others, and for others to respond in an informational exchange. What this may involve is conveying information about shared expectations of individual behaviour with respect to the resources. It is important to stress that communicative interaction as a means to coordinate behavior within a social group sharing a spatial area relies on access to a shared set of concepts, namely a conceptual resource.

With respect to (2), members of social groups have shared aims and goals. The idea is that social groups may not just communicatively interact in order to make the most out of finite resources. Instead, communication is needed to bring about desired outcomes for the group. It is often about achieving the group's shared aims and goals. For example, if a marginalized group is interested in disrupting oppressive structures responsible for the subordination of its members, then communication is needed to coordinate in a way that enables the group to bring about this outcome. And this does not require that members of a social group be in close spatial proximity to one another. The existence of online spaces, for example, allows for the possibility of syndication at a distance. Again, what is important about this is that communicative interaction depends on a shared conceptual resource.

Given (1) and (2), we can suggest the following: A social group $G$ comes to be indirectly related to the conceptual resource of a group $F$ just when the members of $G$ massively overlap with the members of $F$. The idea is that in virtue of being a part of a social group, it is likely that communication is needed to successfully coordinate individuals with respect to finite resources, or else to achieve the shared aims and goals of the group. In virtue of this, members of social groups need to be able to draw on the same concepts that enable successful communication. Hence, members of social groups are related to conceptual resources. However, this relationship is only indirect. Given the conditions of Communication, it will only be the members of the social group $G$ that can communicate with respect to a set of concepts $C$ that will determine whether they belong to a group $F$ that is directly related to $C$. But since the individuals that constitute $F$ are also part of $G$, there is an overlap of members that makes the conceptual resource of $F$ indirectly related to $G$. That is, sometimes $F$ and $G$ have roughly the same members.

One might wonder: Why isn't $G$ the bearer of $C$ if the members use the concepts in $C$ in patterned interactions of communication? The reason why is because the conditions under which a set of concepts is the conceptual resource of a group of people $F$ has little to do with the conditions under which a group of 
people define a social group $G$. Given this, $F$ and $G$ have different modal profiles. ${ }^{21}$ For example, someone can enter into a social group without being able to use any of the concepts that the members use to communicate with one another, yet, since they cannot use the concepts, this person is not a member of the group that is the bearer of the conceptual resource of which such concepts are a part. Hence, though members of a social group can use concepts in communication, it is not the social group itself that is the bearer of a conceptual resource.

Finally, one might further wonder why I talk about an indirect relationship between social groups and conceptual resources when social groups aren't the bearers of conceptual resources: Isn't this just a misattribution? Earlier, I mentioned that there has been important work that has explained how marginalized social groups are able to dissent from dominant hermeneutical realms. In this literature, it appears that theorists talk as if ${ }^{22}$ social groups (i.e., marginalized/ dominant groups) are the bearers of conceptual resources. I think it is important to preserve this talk. After all, talking as if social groups are the bearers of conceptual resources has led to the identification of forms of epistemic injustice; and such findings we must respect. Hence, it is not correct to say that relating conceptual resources to social groups is a mere misattribution. To say otherwise is to ignore the dynamics between social groups, and the concepts that they utilize.

\section{Conclusion}

At the beginning of this paper, I suggested that there are two levels of theorizing about concepts. One is the macro-level that concerns how concepts are involved in our social lives, and the other is the micro-level that concerns concepts themselves. I claimed that there is little interaction between these levels of analysis in existing literature. In this paper, I have tried to bridge a gap between these levels by asking a micro-level question about macro-level conceptual phenomena. I have asked The Resource Question (RQ). RQ queries what it takes for a set of concepts to be the conceptual resource of a group of people. What seems to be a standard answer that is implicit in existing literature on the macro-level functions of concepts is that social groups are bearers of conceptual resources. I have argued that this is the wrong-headed; social groups can't be bearers of conceptual resources. Instead, I suggested that conceptual resources are defined by members using concepts in patterned interactions of communication, and given the nature of how social groups are defined, this will sometimes mean that social groups are indirectly related to conceptual resources.

21. Or different counterfactual instantiation conditions.

22. Albeit, perhaps unknowingly. 


\section{Acknowledgements}

I want to thank the following people for their helpful comments, discussion, and insights during the development of this paper: Stephanie Collins, Madison Griffiths, Karen Jones, Holly Lawford-Smith, Richard Rowland, Laura Schroeter, Kai Tanter, and, most of all, William Tuckwell. Finally, I am grateful to two anonymous referees for their thoughtful and constructive feedback.

\section{References}

Bicchieri, Cristina (2017). Norms in the Wild: How to Diagnose, Measure, and Change Social Norms. Oxford University Press.

Block, Ned (1987). Functional Role and Truth Conditions. Proceedings of the Aristotelian Society, 61, 157-181.

Camp, Elisabeth (2006). Metaphor in the Mind: The Cognition of Metaphor. Philosophy Compass, 1(2), 154-170.

Camp, Elisabeth (2015a). Logical Concepts and Associative Characterizations. In Eric Margolis and Stephen Laurence (Eds.), The Conceptual Mind (591-621). MIT Press.

Camp, Elisabeth (2015b). Why Metaphors Make Good Insults: Perspectives, Presupposition, and Pragmatics. Philosophical Studies, 174(1), 47-64.

Crerar, Charlie (2016). Taboo Hermeneutical Injustice, and Expressively Free Environments. Episteme, 13(2), 195-207.

Dotson, Kristie (2012). A Cautionary Tale: On Limiting Epistemic Oppression. Frontiers: A Journal of Women Studies, 33(1), 24-47.

Epstein, Brian (2015). The Ant Trap. Oxford University Press.

Field, Hartry (1977). Logic, Meaning and Conceptual Role. Journal of Philosophy, 74(7), 379-409.

Fiske, Susan T. and Shelley E. Taylor (1991). Social Cognition (2ed ed.). McGraw-Hill.

Fricker, Miranda (2007). Epistemic Injustice: Power and the Ethics of Knowing. Oxford University Press.

Fricker, Miranda (2017). Epistemic Injustice and the Preservation of Ignorance. In Rik Peels and Martijn Blaauw (Eds.), The Epistemic Dimensions of Ignorance (160-177). Cambridge University Press.

Goetze, Trystan (2018). Hermeneutical Dissent and the Species of Hermeneutical Injustice. Hypatia, 3(1), 73-90.

Goffman, Erving (1961). Encounters: Two Studies in the Sociology of Interaction. BobbsMerrill.

Harman, Gilbert (1987). (Non-solipsistic) Conceptual Role Semantics. In Ernest. Lepore (Ed.), New Direction in Semantics (55-81). Academic Press.

Hartstock, Nancy (1983). The Feminist Standpoint: Developing the Ground for a Specifically Feminist Historical Materialism. In Sandra Harding (Ed.), Feminism and Methodology (157-180). Indiana University Press.

Haslanger, Sally (1995). Ontology and Social Construction. Philosophical Topics, 23(2), 95-125.

Haslanger, Sally (2012). Resisting Reality. Oxford University Press. 
Haslanger, Sally (2013). Social Meaning and Philosophical Method. American Philosophical Association $110^{\text {th }}$ Eastern Division Annual Meeting.

Haslanger, Sally (2015). Social Structure, Narrative and Explanation. Canadian Journal of Philosophy, 45(1), 1-15.

Haslanger, Sally (2016). What is a (Social) Structural Explanation? Philosophical Studies, $173(1), 113-130$.

Hollander, Jocelyn A. and Judith A. Howard (2000). Social Psychological Theories on Social Inequalities. Social Psychology Quarterly, 63(4), 338-351.

Howard, Judith A. (1994). A Social Cognitive Conception of Social Structure. Social Psychology Quarterly, 57(3), 210-227.

Mallon, Ron (2007). A Field Guide to Social Construction. Philosophy Compass, 2(1), 93-108.

Margolis, Eric and Stephen Laurence (Eds.) (1999a). Concepts: Core Readings. MIT Press.

Margolis, Eric and Stephen Laurence (1999b). Concepts and Cognitive Science. In Eric Margolis and Stephen Lawrence (Eds.), Concepts: Core Readings (3-81). MIT Press.

Margolis, Eric and Stephen Laurence (Eds.) (2015). The Conceptual Mind: New Directions in the Study of Concepts. MIT Press.

Mason, Rebecca (2011). Two Kinds of Unknowing. Hypatia, 26(2), 294-307.

McClelland, James L., David E. Rumelhart, and PDP Research Group (1986). Parallel Distributed Processing. Explorations in the Microstructure of Cognition (Vol. 2). MIT Press.

Medina, José (2013). The Epistemology of Resistance: Gender and Racial Oppression, Epistemic Injustice, and the Social Imagination. Oxford University Press.

Peacocke, Christopher (1992). A Study of Concepts. MIT Press.

Pohlhaus, Gaile Jr. (2012). Relational Knowing and Epistemic Injustice: Toward a Theory of Willful Hermeneutical Ignorance. Hypatia, 27(4), 715-735.

Popa-Wyatt, Mihaela and Jeremy L. Wyatt (2017). Slurs, Roles and Power. Philosophical Studies, 175(11), 2879-2906.

Rose, Hilary (1983). Hand, Brain, and Heart: A Feminist Epistemology for the Natural Sciences. Signs, 9(1), 73-90.

Rumelhart, David E. (1998). The Architecture of Mind: A Connectionist Approach. In Paul Thagard (Ed.), Mind Readings: Introductory Selections on Cognitive Science (207-238). MIT Press.

Sewell, William (1992). A Theory of Structure: Duality, Agency, and Transformation. American Journal of Sociology, 98(1), 1-29.

Stanley, Jason (2015). How Propaganda Works. Princeton University Press. 